\title{
Covid-19: Health Education England shares advice for trainees
}

The response to the covid-19 pandemic in England has had a significant impact on doctors' training. Sheona MacLeod, acting director of education and quality at Health Education England, offers guidance

Abi Rimmer

The BMJ

\section{Will rotations in August still take place?}

We're working on plans to allow rotations to take place in August and enable trainees to progress in their careers.

\section{Trainee doctors will be working above and} beyond their usual hours at the moment. Should they still be exception reporting?

Trainees should ensure that their supervisors are aware of the work that they're doing. Exception reporting is a mechanism for ensuring that trainees aren't regularly asked to work in excess of their contracted hours or miss their teaching and, although it's accepted that these are exceptional times, exception reports, where still being used, can help monitor the impact of this pandemic.

\section{What's happening with specialty training recruitment this year?}

Before and after the cancellation of face-to-face recruitment, contingency planning for the continuation of specialty recruitment in 2020 has been one of the highest priorities across the four nations. HEE recognises that those applying for training posts are currently working hard to provide care and we want them to be able to look to the future and progress in their careers. Doctors in training are an essential part of the workforce and recruitment enables the service to have doctors delivering specialist care. Recruitment of trainees ensures the continuation of training and plans have been agreed in order to maintain August 2020 start dates. A letter detailing the principles agreed by the four nations was shared with all applicants and can be accessed on the specialty training website

Trainees are concerned about the reliance on self-assessment to assess their suitability to enter a training programme.

\section{Can you explain why this approach has been taken?}

We're dealing with unprecedented circumstances and in order to facilitate trainees to enter training programmes this year, we've had to adjust the UK recruitment processes.

Full consideration was given to several different assessment models and, with the significant pressure on clinical time, our ability to run any alternative interview processes is severely compromised. It was agreed that the best option for a consistent, deliverable process was self-assessment. This decision was not taken lightly and involved senior clinical representatives from across the four nations, junior doctor representatives from the BMA Junior Doctors Committee and Academy of Medical Royal Colleges trainees' committee, employer representatives, and experts from different specialties, as well as those in the UK Medical and Dental Recruitment and Selection team.

Self-assessment already forms part of the selection process for most specialties. This is therefore a process that applicants are familiar with and, for specialties that use this as part of the standard recruitment process, applicants have already submitted information as part of their application.

How certain are you that no unconscious bias or indirect discrimination has been embedded in this process?

Two different processes are being used to appoint to medical specialty training programmes: situational judgment tests and self-assessment. Both are established means of assessment in standard specialty recruitment processes and significant work has been carried out in the past in several specialties that use these to reduce unconscious bias or indirect discrimination. The selection processes and decisions have been checked with our legal team to confirm that they are justifiable and fair in these circumstances.

What is happening with the annual review of competency progression? What happens if I miss critical progression 


\section{points and can't obtain my certificate of completion of training?}

Trainees who have gathered the required evidence and demonstrated competences will obtain their certificate of completion of training. HEE and our devolved nation partners have been working together to ensure that trainee progression is facilitated where possible. An additional no fault outcome (outcome 10) for those trainees who have not collected the required evidence or acquired the necessary competences as a result of covid-19 has been developed. HEE is working with the royal colleges, the GMC, and other partners to agree the minimum evidence needed at critical progression points. This year some trainees will be able to progress before they have acquired all the usual competences, and to gain them over the next year. HEE is currently planning modified annual reviews of competency progression (ARCP), with amended decision aids, to facilitate this progression.

Four nation guidance on arrangements for ARCPs is on the HEE website (www.hee.nhs.uk/coronavirus-covid-19/coronaviruscovid-19-information-ahps).

\section{If I've returned early from being out of programme or from parental leave will I get the time back?}

HEE recognises the extraordinary effort that trainees have put into supporting clinical services rather than remaining out of programme (OOP). OOP guidance includes recommendations on time back, so that trainees' careers and personal aspirations don't suffer as a result. Parental leave can be split as per statutory position so trainees will still be able to spend time with their young children.

\section{What is HEE doing to support the wellbeing of trainees and making sure they don't burn out?}

HEE is working closely with employers and other partners to ensure that trainees are fully supported at this time. We've been impressed by the initiatives that many employers are putting in place to support healthcare staff and we are supporting wellbeing initiatives with training and guidance, especially for newly graduated doctors. HEE provides specific support from local offices through their professional health and wellbeing services.

HEE also has a package of supported return to training

$\left(\right.$ SuppoRRT $^{1}$ ) resources to help trainees returning to work. This includes a series of webinars led by doctors working as clinical fellows that have been well attended and received and are freely available online.

We're also working with partners to bring back recently retired educators to provide pastoral support to trainees.

All this builds on the work that we've been doing over the past few years in our Enhancing Junior Doctors Working Lives programme. This work has been informed by the views of doctors in training with the BMA Junior Doctors Committee and academy trainees as key partners in the development of initiatives.

\section{Can I be forced to work at one of the Nightingale hospitals?}

No. Working at the Nightingale hospitals is voluntary, although they may also be approved sites for training. See recent guidance which outlines that trainees would need to volunteer. ${ }^{2}$

1 SuppoRRT. https://mysupportt.com.

2 Health Education England. Guidance for postgraduate medical and dental trainees: redeployment to NHS Nightingale Hospitals. April 2020. www.rcseng.ac.uk/-/media/files/ rcs/coronavirus/guidance-trainees-nightingale-hospitals.pdf.

Published by the BMJ Publishing Group Limited. For permission to use (where not already granted under a licence) please go to http://group.bmj.com/group/rights-licensing/ permissions 